\title{
A SELF-CONSCIOUS MISE-EN-SCÈNE: EXPERIMENTING WITH 'DISOWNMENT AND APPROPRIATION'
}

\author{
ANTHONY CRISTIANO
}

\begin{abstract}
Summary: While the historical definition of experimental films as highly personal works, marked by unconventional economic and aestheric norms remains fundamentally unchanged, the context within which they are produced has evolved through the years. This article argues that the contemporary forms of experimental filmmaking are shaped by an artist's personal fears and hopes as dictated by ideologically concomitant and traumatic events. A Self-conscious Mise-en-scène is such a work, and the subject and tools of this investigation: the making of the film amounts to a way of negotiating a communicative crisis, a study of the tendency to misrecognize the bewildering nature of pre-existing realities and disassociate oneself from them before re-inventing and appropriating their meaning and purpose.
\end{abstract}

Recently, an American film festival director asked me the rhetorical question: "What is experimental film? There are so many definitions, everyone has one; and many may think that their film is experimental when it isn't." Besides granting the unorthodox modes of film practice an aura of uniqueness and 'prestigious' status to be somewhat envied, his words underscore the varied character of contemporary experimental and avant-garde filmmaking practice, which defies definition by its very nature. In fact, theoretically there could be as many definitions of what constitutes avant-garde filmmaking as there are unique artists and filmmakers engaged in such a venture. Historically, critics find it convenient to define this 'other' cinema in opposition to Hollywood mainstream cinema, or in virtue of its practices as defined by a recurring set of economic, institutional, and aesthetic norms, or more simply as highly personal films. ${ }^{1}$ These are often self-

${ }^{1}$ An example can be found in Bordwell, "The Art Cinema as a Form of Film Practice"; see also Experimental Cinema, The Film Reader. Some make a distinction between 'art cinema' (i.e. A. Warhol, P. Greenaway) and avant-garde cinema (i.e. S. Brakhage, N. McLaren), adding that in the first case one may also identify a profit-oriented goal. 
financed works, or supported by grants from relevant institutions, and works that take advantage of specialized distribution venues, such as film co-operatives, universities, museums, film societies and the likes. Within the confines of such an ideological context, I would likewise define my recent filmmaking endeavour as an independent and artisanal work. At a recent screening of a segment of my experimental film $A$ Self-conscious Mise-en-scène, together with a version of the current paper, a member of the audience, a film studies professor, spoke of my film as an example of avant-garde cinema, adding that it reminded him of Maya Deren's films. ${ }^{2}$ Besides some similarity in the associational editing style, adopted for example in her film Meshes of the Afternoon, the more immediate similarity I could find with Maya Deren, and which I most cherished, was the effort to comment about and explain one's work. A Self-conscious Mise-en-scène is partly an autobiographical film, attempting to map the psychological workings of the writer and director's inner persona. It is an attempt to deal with fears, hopes and destiny. The key question guiding this essay also applies to the making of the film. The aim is to investigate the contemporary nature of the avant-garde film, specifically pertaining to $A$ Self-conscious Mise-en-scène. how do one's fears, hopes, and desire to fulfill one's sense of being shape the definition of what makes an experimental film?

Having been born in Italy and having spent part of my adolescence there, I am influenced by a realist tradition. When compared to other European cinemas, such as Germany's fantasy-oriented cinema, Italy's century-old literary tradition and its cinema since its golden age at the turn of the twentieth century have been characterized by a marked realism. As a theoretical concept, realism in the cinema is approaching its one-hundredth anniversary and, together with formalism, it is one of the first approaches for understanding the moving images. Like other theoretical concepts, it has been debated and has undergone some changes through the years. ${ }^{3}$ As the world scene evolves and conventions likewise undergo transformation, so does our understanding of the "real" and perception of what constitutes "realism" as an investigative notion. Likewise, the meanings and forms of experimental film have changed together with aesthetic,

${ }^{2}$ The film and accompanying lecture were presented on 27 May 2006 at the annual meetings of the Canadian Society for Italian Studies and on 30 May 2006 at the annual meetings of the Film Studies Association of Canada, both held at York University, Toronto. My interlocutor was Professor André Loiselle (Carleton University).

${ }^{3}$ A study of the notion of realism in the moving images can be found in Black, The Reality Effect: Film Culture and the Graphic Imperative. 
technological, and ideological changes in their societies of origin. I am interested in commenting on and finding explanations for the nature and significance of $A$ Self-conscious Mise-en-scène from a singular perspective, one that in Etienne Souriau's words could be named a 'creational reality.'4

My investigation is conducted from the advantageous, if biased, position of the author of the work under scrutiny. The broader objectives of this study, which is only introduced here and not limited to $A$ Self-conscious Mise-en-scène, are to contribute in telling the story of an independent filmmaker by investigating the dynamics of what I call 'disownment and appropriation' from one's place of origin, a European culture, to one of migration, a North American cultural setting. This study will also discuss autobiographical creation/research and the principles, if any, that govern the study of the processes of cultural disorientation and resettlement as these are translated into artistic activity. The subsequent release and publication of the works, like $A$ Self-conscious Mise-en-scène and related critical material, are meant to become part of the records of a contemporary Canadian filmmaker of Italian origin and the self-conscious workings of a 'two-world' memory. There are no prescriptive theories that apply to this specific process of investigating one's own artistic work and recording one's biography, for they would necessarily be limitative in matter of method and scope. I shall therefore opt for the standard method of positing legitimate questions based on my academic interests, as exemplified in the making of $A$ Self-conscious Mise-en-scène, and subsequently attempt to conceive answers that appear reasonable and logical.

The theoretical questions guiding my arguments have to do with the purpose served by the arts and their principles and results. What purpose does experimental filmmaking serve today? Have its traditional aims to challenge, subvert, and renew, changed? What is the contemporary context in which an artist and researcher works? What effect, if any, does this have on what is being created or produced? Thus, what cultural and aesthetic principles guide the making of $A$ Self-conscious Mise-en-scène? How are these evidenced within the cinematic text? How does the artist's self-criticism differ from the customary criticism offered by third party critics? What is meant by 'dynamics of disownment and appropriation'? How might this notion provide a model for an investigation of the work?

${ }^{4}$ In the 1950 s Etienne Souriau identified seven categories of film realities, including the category of 'spectatorial reality.' Among the new terms he coined is the widely used term 'profilmic (reality),' Souriau, "La structure de l'univers filmique et le vocabulaire de la filmologie." 
My cultural character and aesthetic style is informed in part by my Italian and Canadian education and experience of the arts. Evidence of this influence may be found in the material inspiring the film. The short story on which my film is based is an example of my interest in the real, an unembellished story of every-day-life, a concrete event I have witnessed. The narrating voice of the character Gabriele recalls the homeless people seen on the streets of Rome and then those he finds on the streets of Toronto in the hot summer of 2000 . The short story was written before 11 September 2001, whereas the film was made after that tragic date and bears the tension and sense of fear of the new era. As a result, the film may be viewed as blending the latter climate to the preceding one. After meditating on the parallel between physical and intellectual needs, and how they may be closely related, the narrator imagines his own descent into homelessness in an effort to understand and empathize with the people he regularly meets stranded on the sidewalks of his neighbourhood.

There is no place for disquisitions on historical, linguistic, and cultural differences between the cities of Rome and Toronto: the conspicuousness and immediacy of the subject matter bridges the two cultures and distant countries over one global issue within the short story. 5 In the author's mind, the urgency to satisfy a basic human need and the sense of human drama depicted in the short story surpass societal and other cultural differences between Italy and Canada. The plight of destitute people wandering the streets of a big city appears to be the same, regardless of whether these individuals are seen on the streets of Rome or of Toronto. No matter how foreign the context, these subjects appear oxymoronically familiar: the re-emerging of a mentally recurring image transcending environmental differences in the filmmaker's consciousness. He is interested in lending help, but is not able to bring a real solution to the problem. The ensuing conflict in the author is transposed to the writing and making of an unconventional film. The nature of the project and type of engagement it demands mirror the same sense of 'separation,' 'out of the mainstream,' 'otherness,' and 'contrast' manifested by the homeless people on whose dilemma he dwells. The lives of these destitute human beings cause concerned individuals, witnessing their poverty, to re-think the fundamental principles of life. In a similar way, A Self-conscious Mise-en-scène, by focusing on the inner turmoil generated by the awareness of the plight that confronts the author, proposes a re-thinking of the conceptions or preconceptions about the nature and function of film.

5 The short story "The Millenary Man" appears in Cristiano, The Graviton. 
The first film theorists, although with differing arguments, ascribed to the camera the ability to capture reality in unparalleled ways. Realist schools of thought, such as what in the canon of global cinema came to be known as "Italian neorealism," capitalized on this presumed prerogative of the photographic medium by producing emotionally charged films of great social impact. ${ }^{6}$ On the other front, from the 1920 s and throughout World War 'Two, the first avant-garde filmmakers-Fernand Léger, Marcel Duchamp, Robert Florey, Slavko Vorkapich, Mary Ellen Bute, Francis Lee, George L. K. Morris, Norman McLaren, and others-had already produced many examples of unconventional use of the tools of filmmaking. Theirs was an exploration into photography, texture, subject matter, narrative, composition, montage, and perception that made the viewer rethink the use and purpose of the entire apparatus of the cinema. During the 1940s and into the 1950s Maya Deren explored the world of dreams. She experimented with mise-en-scène, choreography, and montage and imbued her films with a peculiarly female sensibility which, in the opinion of some enthusiastic critics, made her the first avant-garde woman filmmaker. ${ }^{8}$

In 2000 Stan Brakhage honoured Maya Deren's art by making a film titled Water for Maya in tribute to her work. From the 1960s until his death in 2003, Brakhage himself engaged in a long experimentation with the physical processes of film. He experimented with the material, its chemical components, and the exposure process. Guided by a lyrical abstractism he made hundreds of intensely subjective films, the last of which he scratched with his nails and embedded with his own saliva while hospitalized for cancer. ${ }^{9}$

${ }^{6}$ For discussions on neorealism see: Zavattini, "Some Ideas on the Cinema"; Nowell-Smith, "Cinema Nuovo and Neo-Realism; Marcus, Italian Film in the Light of Neorealism.

${ }^{7}$ Among the groundbreaking experimental works: Ballet Mechanic, 1923 by F. Léger and D. Murphy; Anemic Cinema, 1924 by M. Duchamp; 9413 Life and Death of an Extra, 1927 by R. Florey and S. Vorkapich; Rhythm in Light, 1934 by M. Webber and M. E. Bute; Synchronym, 1936 by M. E. Bute and T. Nemeth; Scherzo, 1939 by N. McLaren; 1941, 1941 by Francis Lee; Abstract Movies, 1939-1947 by George L. K. Morris.

${ }^{8}$ Meshes of the Afternoon, made in 1943, is considered her most influential film. Criticism of her work can be found in Nichols, Maya Deren and the American Avant-Garde.

${ }^{9}$ Stan Brakhage made over 370 films. For a discussion of the man and his work see James, Stan Brakhage: Filmmaker. 
At the beginning of the twenty-first century the movie camera and all other innovative and old processes utilized to make films are still a means of exploration in the hands of new generations of experimental filmmakers. The prolific generations of avant-garde filmmakers of the $1960 \mathrm{~s}$ and 1970s, which included independent artists such as Stan Brakhage, Robert Breer, Andy Warhol, and Michael Snow, ${ }^{10}$ were conveniently categorized into underground and structuralist movements. The failure to identify a subsequent group did not extinguish the avant-garde drive within the world of moving images. Critics of postmodernism who speak of a culmination of sorts and of the new aesthetics and experimental films as a 'revolutionary pantomime' or as an 'oxymoronic tradition of the new'll do not affect the innovative propulsion and fertility of an emerging generation of independent filmmakers. Inspired by previous works, A Self-conscious Miseen-scène also intends to subvert contemporary standard formulas of filmmaking and storytelling by emphasizing important elements of its own mechanisms in ways rarely seen in the cinema. In line with the characteristically limited, and mostly private, resources experimental filmmakers can afford, A Self-conscious Mise-en-scène was shot on approximately 3,300 feet of $16 \mathrm{~mm}$ black and white Kodak 7222 100DXN455 film: a total of 33 cans of film. Unlike our American neighbours who have a long history of private investment in the cinematic arts, the Canadian independent filmmakers' context is characterized by a tiring reliance on public financing. While such a scenario may carry a degree of creative freedom, one's cultural setting and limited resources may also be conditioning factors for the type of projects endorsed. The experimental nature of A Self-conscious Mise-enscène was shaped in positive and less positive ways by such circumstances. Its unpolished texture reveals its choice in matter of means and aesthetics. Its black and white 'dirty' density look contrasts with the neatly balanced colours of a regular film and, unlike the invisible montage assured by the continuity style, its 'self-conscious modus operandi exposes its construction process. It makes visible elements of its mise-en-scène procedure such as the setting up of the scene, its composition process, and various actions surrounding the performances, integrating these elements in unusual ways into the atypical narrative. Further, unlike the 'structural-material' films of

10 Notable works: Dog Star Man I-IV, 1962-64 by S. Brakhage; 69, 1969 by R. Breer; Empire, 1964, and Chelsea Girls, 1966 by A. Warhol; Wavelength, 1967 by Michael Snow.

${ }^{11}$ See Butler, After the Wake: The Contemporary Avant-Garde, and Hoberman, Vulgar Modernism: Writings on Movies and Other Media. 
previous generations, the experiment goes explicitly beyond the properties of film. To be political, it does not need to demystify the means by which it is being made, as Peter Gidal maintains in reference to previous generations. ${ }^{12}$ A Self-conscious Mise-en-scène's radical implications invest a broader spectrum of old and new elements involved in the contemporary forms taken by experimental filmmaking.

The contemporary world context has evolved vis-à-vis an obstinate desire to find new answers to old questions. As an artist and researcher I continue to question the meaning and purpose of the processes in which I engage. What meaning does the 'reality' I am working in have? What meaning does it have to those who perceive it later, as a 'completed work'? Every new generation, seems 'naturally' inclined to question and challenge the traditional modes and conventions, which define the arts and the social milieu surrounding them. The tendency to misrecognize these pre-existing realities and disassociate oneself from them before re-defining their nature and re-inventing their meaning and purpose seems to be part of a long and complex development process. This is a process that I call 'disownment and appropriation.' 13

I believe I have experienced this process as an immigrant by seeking to build an identity in a new country; growing new roots in its soil while preserving and cherishing what in my case is a European background. I have also experienced this process as an independent filmmaker who explores the medium as a novel art form that offers possibilities that are to be discovered and appropriated before they can be fully appreciated. Settling in a foreign land requires one to adapt to new customs, acclimatize to a new environment, and learn the nuances of a new language and culture. It is an exploration of unknown territory and as such it carries the risk of being a traumatizing experience. Likewise, when initiated into the art of filmmaking one is unfamiliar at first with its workings and intricacies. The fruitful bond with the mechanisms of making films and the expertise that will yield enjoyment and actual results does not exist and one feels detached and awkwardly at odds with the craft he is posed to understand. This sense of 'distance,' of 'misrecognition', of 'disorientation,' and the initial predicament of conflict towards that to which one is not accustomed, generate

\section{${ }^{12}$ See Gidal, Materialist Film.}

${ }^{13}$ Mine is not meant to be a Freudian psychoanalytical approach and I do not intend to be weighed down by the paradigm of Lacanian psychoanalytical theory of the 'mirror stage' in a child's psychological past here. Rather, I refer to my experience as a cognitive adult and try to describe it concretely in this fashion. 
tension and anxiety. The inability to summon one's sentiment and record it on film in order to communicate with orhers is likewise a source of much distress for a filmmaker interested in the medium as a means of self-expression. Much labour is required to overcome such an impasse, but when one prevails a profound sense of communion is reached. It amounts to an experience of growth, from a state of self-consciousness and disorientation to one of self-confidence and determination. I conveniently name this course from one emotional and psychological state to another a process of 'disownment and appropriation.'

I have witnessed a similar excitement in my film class students when they learned how to verbalize their understanding of a film, just as a filmmaker learns how to give visual forms to his or her feelings. Others may erroneously believe to be inventing a new language simply by opposing an existing trend, policy, or ideology, when in reality they are appropriating a centuries-old coded system and the self-confidence to display their opposition. ${ }^{14} \mathrm{~A}$ communicative crisis within one's society may also precede a state of 'disownment,' of 'homeless mind,' which may likewise require the appropriation of a 'destination' point. To find ways to integrate the proceedings of such a course of action into the experimentation of one's craft, in this case the making of an experimental film, becomes a practice of avant-garde cinema, that is, a push of the functions and purposes afforded by this particular art form. A notable theorist of the history and notion of avant-gardism, Renato Poggioli, referred to the concept of ceaseless selfcritic as an example of the modernist era. He considered any 'ideology' to be a social phenomenon and wrote that, "in the case of the avant-garde, it is an argument of self-assertion or self-defence used by society in the strict sense against society in the larger sense." 15 The trajectory is not that simple and Poggioli realized that the relation between society and the direction taken by the avant-garde is a complex one that required a study of an equally complex phenomenon of "alienation."16 In my case, I take an active approach, by first disowning that which I seek to appropriate through the creation and releasing of the film.

A Self-conscious Mise-en-scène is a visible manifestation of such a com-

${ }^{14}$ The question whether the cinema can be compared to a language or a language system is still a complex and open debate, let alone the idea of a new language' of, or for, film. Notably, Christian Metz made a systematic effort, beginning in the 1970 s, to create a grammar for the cinema.

15Poggioli, The Theory of the Avant-Garde, pp. 1-5.

16Poggioli, The Theory of the Avant-Garde, pp. 102-125. 
plex rapport with the world it tries to depict. The sentiment of anxiety mixed with fear informing the film also finds an outlet in the music score. The inclusion and treatment of extra-diegetic sounds in the film serve to evoke this feeling, at times one of contrappunto, at other times a sense of 'becoming,' of 'taking shape'; the sounds of 'things in the process of being built.' These sounds originate from a variety of sources such as scrubbing glasses, water drops, pot lids, water taps, ladles and the like. The choice of sounds was dictated by a constant sense of angst; a dramatic feeling originating from an imperturbable state of anxiety. The result is an aesthetically uncharacteristic film, which mirrors the development of a new sense of being. The making of the film becomes the means through which I voice a course of 'acclimatization,' of acceptance into an unknown surrounding, of gradual re-settlement and integration into a new cultural and social context. In $A$ Self-conscious Mise-en-scène I try to incorporate this reality into the unconventional narrative adopted, with the aim of making the viewer a participant in the same construction of meaning from the 'receiver's' end. My film may present aspects of what many new productions do when they shoot "the making of..." while producing the actual film and then add the ensuing documentary as an extra feature to the DVD release. ${ }^{17}$ However, A Self-conscious Mise-en-scène does not include a separate documentary because the actual film includes unembellished portions of the setting up of the scene, the sounds surrounding the mise-en-scène, uncut segments of film with 'white' glares and hands covering the lens, impromptus, false starts, and 'mistakes' made by the performers. What defines the film's "selfconsciousness" is the choice of sewing patterns of the same into the diegesis of the film.

Practically, I do this by constructing unusual configurations out of 'unedited,' 'unclean,' portions of film, and by making atypical associations of images and unconventional sounds. I create unaccustomed forms, the meaning of which is not readily decipherable according to standard formulas of filmmaking, and I unabashedly present it all to the viewers' eyes and ears. As creator of the work, in the role of writer, director, producer, and editor, I am conscious of subverting a standard procedure, of challenging the predictable use of film, of experimenting with the medium, of the limits associated with my degree of expertise, and of the freedom afforded by the unconventional choice made. Such a procedure is not nec-

${ }^{17}$ The innovative choices of extra features offered by the introduction of digital versatile disks have changed the viewing habits, perception and expectations, of the general public renting the home-viewing devices. 
essarily different from the processes adopted by Maya Deren, Stan Brakhage, Michael Snow, or from the approaches taken by peer artists in Halifax and Toronto. The singular characteristic of A Self-conscious Miseen-scène or of any other experimental film lies in the extent to which the patterns presented are the peculiar manifestation of a different voice and personal style. In my case, originality and authenticity lie in the way in which personal anxieties, fears, hopes, achievements, and future goals associated with my activity, have inspired and shaped the nature and outcome of the experimental work.

On the one-hundredth anniversary of the Lumière brothers' original movie camera, forty filmmakers were invited to celebrate the event by each making a one-shot-film, 52 seconds long, using an original 1895 camera. ${ }^{18}$ Among the directors participating in the celebratory event were Wim Wenders, Liv Ullmann, John Boorman, Cluade Lelouch, Abbas Kiarostami, Lasse Hallström, James Ivory, Spike Lee, Peter Greenaway, Arthur Penn, David Lynch, Theo Agelopoulos and others. After each piece the directors were briefly interviewed. I was particularly interested in the answers given by some of them to the question pourquoi filmez-vous? Why do they make films, and how was their decision determined by the circumstances each of them found her/himself in? My interest is sparked by a growing sense of 'familiarity' I have developed with this particular art form and by how it has slowly become an agency for the making of an identity: my attempt as a grown-up to transcribe my own psychological conflict and state of anxiety as I settle in North America with a renewed awareness of an old quandary. My mind travels across the two worlds of which it preserves memories. I recall the streets of the big cities I have walked, the various homeless people I encountered, and the deep-rooted fears I still harbour within me. I too have enjoyed the playfulness partly associated with the making of a film but unlike others I do not, or cannot afford to, make films as if it were the 'only thing I know' or 'am familiar with.' I am working on A Self-conscious Mise-en-scène out of necessity, the necessity to voice my inner dilemmas and understand my surroundings. The film becomes the channel through which I express my long meditated thoughts, the tabula on which I transpose the activity of my intellect and give it visible forms. The purpose lies in the act of 'making and becoming,' and one important goal is to make an artist's identity open to scrutiny and comprehension. In such a context filmmaking is an opportunity to dispense light on the occasional, or underlying, 'strangeness' of one's feel-

${ }^{18}$ Directed by Sarah Moon, Lumière et Compagnie (Fr. 92 min., b/w \& col. 1995). 
ings. It offers the occasion to evaluate one's relation to others and the world and a further means to bridge understanding. I do not feel the need to displace my interest from the conflictual sense of reality I am confronted with to filmmaking as an act of avant-garde écriture for its own sake. ${ }^{19}$

One of the guiding principles in the making of this piece of autobiographical work has been to emphasize the unusual, to shed one's conventional approach and forge an unadulterated one. This occurred in the production stage while filming the profilmic reality with a sense of curiosity towards the domesticity of the places and objects filling the mise-en-scène, as if they were seen for the first time. Likewise, in the post-production stage I probed into the actors' performance, as into a reflective surface, and valued the sense of discomfort as the more revelatory and authentic moments of their act. I have purposely and visibly incorporated these takes into the atypical diegesis; an unorthodox move by standard procedures that attempt to purge the narrative of such 'bloopers.' The creator of the work is in a better position to access the motivations leading to these approaches; the critical insight afforded by 'self-criticism' enjoys an analytical advantage in virtue of such awareness. The creator/researcher is able to speak confidently of the 'why' and the 'how' invested in the film, and subsequently the viewer receives a 'first hand' description and appraisal of the nature of the work via the mind from which it originated.

In the cinematic text the narration of the story occurs in the third person and by the letter; one after another various third-person narrators, 8 males and 7 females, are placed in front of the camera and asked to re-tell the story of Gabriele as if it were their own, laboriously and word by word, while the same actors are in turn juxtaposed during the montage, at varied pace, with ordinary objects, such as refrigerator, stove, diary, paper, ink, books, rainfall, balcony, and then streets, cars, shadows of homeless people shaking coffee cups, and other scenes. The struggle at assembling the film in meaningful patterns mirrors the difficulty to appropriate the significance of the items and scenes captured, as if seen for the first time. The performers' unevenness in delivering their lines resembles the difficulty of understanding the 'foreign' story of others, and of coping with an unsettling and ominously recurrent image of displaced people, whose actual story remains unknown. The peripheral existence led by these individuals who have disowned a conventional lifestyle and who in turn have been tacitly disclaimed by society, in artistic terms is paralleled by the isolated and

${ }^{19}$ The French New Wave directors are said to have been particularly fond of the scriptural metaphor comparing the camera to a pen. 
solitary activity of recording on paper and assembling on film the likewise troublesome experience of coming to terms with one's shattered sense of identity.

The effort to recognize and appropriate what should be one's domestic surroundings, in the country of newly acquired citizenship, is only part of a deeper sense of displacement. Working on the fringes of a dominant, and commercially oriented culture industry, and being unable to impact its ephemeral vision of the world, engages the artist in a battle to counteract an advancing state of confusion and a general loss of meaning. The apparent easy access to technological means on one hand presents a less appealing side of subtle regimentation on the other. ${ }^{20}$ The plight of an impoverished people and the fears associated with such a state, intersect the anxiety and quandary bred by a detached and 'homeless mind' in the artist. In such a context the cities visited become a site of 'lost paradise.' My reminiscences of the Italian landscape, particularly of the city of Rome as recalled in the film, is dominated by the inclusion in the narrative of the older homeless woman's tale. I met her on the streets of the quartiere Tiburtino while returning home after having been to a theatre play in the heart of the city. I was struck by her confidence as she asked to stay at my place for the night and by her insistence on following me despite my refusal to accommodate her request. More than ten years later I am conscious of the experience and the memory of her haunts me, to the point of having now forced itself onto the film. The act of delivering these memories is aided by the use of maps and the presence of a music score, in this case the singing of lyrics accompanying the images and reiterating the older woman's predicament. The re-appearance of equally destitute individuals on the streets of Toronto becomes the anchor points of a metonymical bridge bonding the two continents, and in virtue of the fundamental dilemma these realities summon in my heart, any linguistic and cultural differences between the two societies are adumbrated in my mind. In fact, possibly because of the education received both in Italy and Canada, I found myself less concerned with socio-cultural shock-or perhaps better equipped to shield its impact-and mostly drawn to the inexplicable inner structures that regulate one's tormented relationship with the 'strangeness' perceived in the world.

\footnotetext{
20 Whereas the 1960s 'underground cinema' and 1970s 'new underground cinema' may have meant pluralism and liberation for some, today the niches created by film clubs and film co-ops in Canada and their struggle to survive may suggest a broader ideological conundrum.
} 
As an eighty-minute feature-length experimental film $A$ Self-conscious Mise-en-scène gives me the opportunity to communicate visually to others the experience described in this article. I found it useful to divide the film into two chapters, each in turn divided into shorter units, which are linked to one another by means of suitable transitions. In the first half I have placed the performers in parallel to the flow of the short story in order to narrate Gabriele's tale, as described earlier. I have devoted the second chapter to the assemblage of the outtakes and to the director's commentary. Here I shall record, by means of voice-over, in essence the meaning of the entire experience, its workings and its purpose, as discussed above.

I will conclude this discussion by examining a portion of the film with reference to images, music score, and apparent 'slips' made by the actors. About half way into the first chapter, I created a montage of two different actors, who on the film set were asked at one point to deliver separately the same lines to the camera. The sequence showing them inter-cut together is preceded by an image of a paper vessel sitting on a desk and made out of a ripped page of diary where the short story inspiring the film is being written. On the soundtrack the sounds of crushing waves and then of water drops are heard. Each actor conveys an idiosyncratic feeling as he or she speaks to the camera. The lines delivered in this montage, starting with the first performer, are the following: "How many times has he found himself alone at home / the park or the villa / the seashore or lakeshore / pleading within himself / in dire need of fulfilment, depth and belonging / aren't those the same things the people on the streets, the homeless, have ended up disgracing themselves for?" In this case, the two male actors deliver a peculiarly different performance, the first somewhat aggressive and the second mellowed thus making a personal contribution to the picture and to its distinctive style. The motivating thought, as supported by their words and personal tone, is the same: an unsettling sense of angst. They draw a strong resemblance between the struggles of solitary homeless people in need of a warm welcome and those of the narrating voice, a distraught man, who yearns for a deeper sense of fulfilment. The existential crisis being described appears to be the same, to the point that the stages alone make up for any apparent difference. What is being projected here is a natural willingness to show empathy to fellow human beings. The sequence is scored by a crescendo sound of water drops. At the end we momentarily return to the first performer as he gives a poised look at the camera before leaving the scene while a third actor makes his entrance and silently stands in front of the camera for a moment.

The noise of water running in a bathtub is heard and soon after we see 
images of the water and then two paper vessels 'sailing' in a filled bathtub. A shot of the third actor follows; he speaks of a "haunting feeling in the air, the need to hear that everyone is doing fine, no disturbing words or bad news." The sound of the water is meant as an appeasing echo, which should replace the referenced "disturbing words." The images involving water have a duplicate function, that of retrieving a playful and idyllic picture, one beyond the city as a site of 'lost paradise,' and the other the corroding power of an insistent drip, that of a persistent struggle and irremovable fear. The next sequence shows a hand wiping a drop of ink, the same ink used to write the short story, while a tenor's voice sings "all day, all day, all day / open hand." In the following close-up shot the drop of ink appears at the bottom of a glass filled with clear water; it keeps expanding and slowly rises, in the form of abstract shapes, towards the surface. The sound of water drops re-emerges as the incongruous and dreamlike sequence unfolds under the viewer's eyes. These sounds are given different pitch, which turns them into a melodic sequence. The resulting sound is that of a strange ticking, similar to that of a clock reminding us that time is running fast. This particular scene evokes feelings associated with a somewhat 'amorphous state,' the confused sentiment of the one who is in search of a place where rest for the mind is found. It is the attempt at representing the wish to envision the world as a place of appeasing echoes, regardless of the particular mores of one place versus another. What may initially appear as poisonous figures may be viewed as pictorial forms stimulating one's imagination or fantasy. ${ }^{21}$

Exposing one's imperfect state becomes a necessary step to break or halt the deleterious impact of such a condition, and ultimately part of a process of liberation. Throughout the film several actors are caught in what is traditionally considered a slip on their part. While this may be true in a standard narrative, in A Self-conscious Mise-en-scène these 'accidents' take on a function. Starting with an early scene, one actor, after making what to him appears a 'mistake,' snaps his fingers and while looking at the director says, "start again?" Shortly after, a different actor also makes a false start and says, "I screwed up... Start again?" Both cases are followed by a shot that is complementary to its predecessor: a paper ripped from a personal diary is trashed as useless. A third actor, after realizing he has somewhat

${ }^{21}$ While according to contemporary notions of realism, in film reality and fantasy remain separate entities, in his 2002 book Joel Black argues that this could change with the further erosion of the boundary between real and virtual, see pp. 30-32. 
taken the story in a different direction by 'forgetting' his lines, slows down, and then resumes his delivery without intentionally interrupting the flow of the sequence. In standard narratives scenes similar to the ones described above would be 'trashed' in the edit bin. They interrupt the 'natural flow' of the story and interfere with the continuity, which demands that the 'edits' be invisible to the viewer. A Self-conscious Mise-en-scène purposefully keeps these sequences as integral to its unembellished construct, original 'material,' and ultimately its filmic text. It is an unconventional, untraditional, and thus innovative and avant-garde move in that it provocatively retains and incorporates the alleged 'mistakes' made by speaking-roleactors as part of its story. The performers are as much part of the story as the tale they try to appropriate and deliver to the camera. The story being told is equally made of the process engaged to narrate it. Once on the screen, these unorthodox scenes must be regarded as equally depicting the pictorial world they are a representation of. They are no longer 'slips' but enlightening actions embedded in the unusual narrative.

What is the broader significance of such a choice? It affects the filmmaker and viewer's perspectives on the meaning and functions of the cinema beyond its traditional confines. It is a way of mirroring oneself in one's artistic activity, as in a reflective surface. It amounts to a form of discovery; realizing in the art of filmmaking the function to meet a fundamental human need, that of providing a transfigured image of one's inner persona, one's recessed struggles and fears. It contributes in publicly legitimizing an artist's identity and it equally endorses the legitimacy of the ensuing struggle as invested in the making and releasing of a film. It provides the material forms to translate and confront one's course of adjustment and development into a new cultural and social context, and the means to communicate and share its experience with others. It is conducive to the process that disowns the strangeness of one's inner self to appropriate a renewed, reinvigorated sense of being. Consequently, in one important instance the film becomes the agency for the making of an identity, the survival of which depends on the successful outcome of the final work.

\section{Dalhousie University}

\section{Works Cited}

Astruc, Alexander. "The Birth of a New Avant-Garde: La Camera-Style, in The New Wave, ed. Peter Graham. London, UK: Secker \& Warburg, 1968.

Black, Joel. The Reality Effect: Film Culture and the Graphic Imperative. New York,

NY: Routledge, 2002. 
Bordwell, David. "The Art Cinema as a Form of Film Practice." Film Criticism 4:1 (Fall 1979): 56-64.

Butler, Christopher. After the Wake: The Contemporary Avant-Garde. Oxford, UK: Clarendon Press, 1980.

Cristiano, Anthony. The Graviton. Toronto: Polypus Publishing, 2002.

Experimental Cinema, The Film Reader. eds. Wheeler Winston Dixon and Gwendolyn Audrey Foster. New York, NY: Routledge, 2002.

Gidal, Peter. Materialist Film. London, UK: Routledge, 1989.

Hoberman, J. Vulgar Modernism: Writings on Movies and Other Media. Philadelphia, PA: Temple University Press, 1991.

James, David E. Stan Brakhage: Filmmaker. Philadelphia, PA: Temple University Press, 1991.

Marcus, Millicent. Italian Film in the Light of Neorealism. Princeton, NJ: Princeton University Press, 1986.

Metz, Christian. Film Language: A Semiotics of the Cinema. New York, NY: Oxford University Press, 1974.

Metz, Christian. The Imaginary Signifier: Psychoanalysis and the Cinema. Bloomington, IN: Indiana University Press, 1982.

Nichols, Bill. Maya Deren and the American Avant-Garde. Berkley, CA: University of California Press, 2001.

Nowell-Smith, Geoffrey. "Cinema Nuovo and Neo-Realism, Screen, 17:4 (Winter 1976-1977): 111-117.

Poggioli, Renato. The Theory of the Avant-Garde. Cambridge, MA: Harvard University Press, 1981.

Souriau, Etienne. "La structure de l'univers filmique et le vocabulaire de la filmologie," Revue Internationale de Filmologie 7-8 (1951): 231-240.

Zavattini, Cesare. "Some Ideas on the Cinema," Sight and Sound, 23:2 (Oct. 1953): 64-69. 